\title{
Hellín García, María José y Corbalán Vélez, Ana (eds.) (2019): Todos a movilizarse: Protesta y activismo social en la España del siglo XXI. Barcelona: Anthropos Editorial, 224 pp. ISBN: 9788417556204.
}

El libro Todos a movilizarse: Protesta y activismo social en la España del siglo XXI reúne las diferentes reacciones sociales a temas de gran actualidad. Con el objetivo de dar visibilidad a la militancia política, a través de doce capítulos de diferente autoría, se da respuesta de manera lineal a preguntas como qué es el activismo, cuál es el papel del arte o cuáles son las formas de protesta social más recurrentes, entre otras.

Ana María Díaz-Marzos, autora del primer capítulo, recoge la denuncia de la presión estética y la violencia simbólica que sufre el cuerpo de la mujer. Para ello, examina el trabajo de cuatro artistas españolas contemporáneas: Pilar Albarracín, Yolanda Domínguez, Raquel Riba Rossy y Cinta Tort Cartró (Zinteta). Este capítulo demuestra el nexo entre política y estética, activismo y feminismo, entendido este último como un programa para la acción que empodera de un modo radical el papel y el cuerpo de la mujer. Centrándose en los elementos visuales de este tipo de activismo, destaca, por ejemplo, la acción Azafatas (2012) de Domínguez en la que se denunciaba el rol de mujer florero de las azafatas o el vídeo "Furor Latino" (2003) de Albarracín sobre la cosificación de la mujer.

En el segundo capítulo, María Camí-Vela se pregunta si España es el epicentro de la cuarta ola feminista. Su análisis gira en torno a tres acciones sociales: el "El tren de la libertad", un documental contra el anteproyecto de ley de aborto que pretendía, de nuevo, su tipificación en el Código Penal, la multitudinaria huelga feminista del 8 de marzo de 2018 y la campaña \#Cuéntalo. La autora señala que estas tres acciones y la cuarta ola feminista tienen en común la unión estructural entre la opresión de género y el capitalismo. La sororidad entre mujeres, como base de estas movilizaciones, es clave para denunciar la violencia de género, la feminización de la pobreza o la precarización de la mujer en el mundo laboral. A pesar de que no enumera los logros de estos movimientos sociales, la autora los considera como un éxito en sí mismos y propone, como siguiente paso, trasladar el activismo al Parlamento.

Siguiendo con el feminismo en España, Ana Corbalán analiza, en el capítulo tres, el activismo social en el mundo laboral, cultural, el cine, la música y los medios de comunicación. Del primer ámbito, la autora destaca el Club de Malasmadres a través del cual hace emerger el término corresponsabilidad, de Pérez Orozco, para enfatizar el papel de los roles masculinos en la lucha contra la escasez de tiempo libre de las madres trabajadoras y el techo de cristal. Clásicas y Modernas y + Mujeres, por su parte, son otro movimiento que reivindica la igualdad de género en la cultura a través de manifiestos, jornadas, conferencias, tertulias e incluso manifestaciones. En el ámbito cinematográfico y musical, CIMA y MIM son las dos agrupaciones más representativas por su larga trayectoria, la primera, y por sus eventos formativos $y$ culturales la segunda. Finalmente, destaca la investigación de Alicia Montano, editora de igualdad de TVE, para eliminar la brecha de género y generar concienciación social.

El cuarto capítulo, escrito por Marina Bettaglio, gira en torno al reparto desigual de las tareas de cuidados debido al modelo de subordinación que ha originado el neoliberalismo actual. Bettaglio se centra en las acciones de la Plataforma por Permisos Iguales e Intransferibles de Nacimiento y Adopción (PPiiNA) que busca equiparar los permisos de paternidad a través, por ejemplo, de la página web igualeseintransferibles.org. Como resultado de su lucha, destaca la aprobación del Decreto-ley 6/2019 sobre el aumento del permiso de paternidad, pero se lamenta, en palabras de Pazos Morán, cofundadora de la plataforma, que esta ley no pueda ser capaz de cambiar los patrones de conducta masculina. Además, partiendo de concepciones ecofeministas, la autora expone que el apoyo de hombres profeministas es clave en una reorganización social sin dominación.

Sin duda, el capítulo quinto, por Txetxu Aguado, es el más excéntrico por su análisis de la lucha femenina a través de la desnudez en dos grupos: Femen-España y la procesión del Coño Insumiso. Aguado justifica el modus operandi de estas organizaciones mediante la teoría de Agamben sobre la desnudez y su relación con el pecado y la teoría de visibilidad extrema de Linda Williams. Por un lado, el grupo Femen protesta contra la explotación laboral y sexual, el turismo sexual, la prostitución y la cosificación del cuerpo de la mujer para el disfrute del hombre. El autor se hace eco de que los cuerpos de estas mujeres se consideran heteronormativos, aunque sin especificar si es algo deliberado o no. Por otro lado, elogia las acciones del Coño Insumiso, una procesión anti-modestia y un Manifiesto, para reivindicar la objetivación del cuerpo femenino, el derecho de las mujeres a sentir placer, y la visibilidad e insumisión del género femenino, aunque concluye que su efectividad no puede ser comprobada a corto plazo.

En el capítulo seis, Carolina Fernández Cordero adentra al lector en el mundo del arte y relata la emergencia de grupos musicales como respuesta para subvertir los roles sociales impuestos en tres escenarios diferentes. El primero son las actuaciones callejeras, concretamente los grupos de batucadas, algunos extremistas solo para mujeres, que buscan demostrar que la mujer es capaz de cargar y resistir durante horas 
instrumentos pesados como el tambor. Del segundo escenario, los espectáculos estáticos, Fernández analiza En (de)construcción, de Ashabá, que se articula a través de una pirámide materializada en cajas que simula la sociedad patriarcal y la escalada de la violencia machista. Así, en la base, busca concienciar sobre las violencias más normalizadas, hasta llegar a las violaciones y feminicidios en la cúspide; momento culmen de la obra que da lugar a un espacio en el que poder reflexionar de manera conjunta. El último escenario son los espacios en los que se forma en la percusión con perspectiva de género. Es decir, talleres autoorganizados y autogestionados por mujeres que buscan reflexionar y denunciar la violencia de género.

Jorge González del Pozo analiza, en el capítulo 7, la película de Achero Mañas Noviembre (2003) como germen del activismo local, ya que esta narra la historia de un grupo de teatro madrileño del mismo nombre que busca cambiar el mundo a través de sus obras. El autor, desde una perspectiva actual, propone el arte como una expresión premonitoria del activismo que tendría lugar tras la crisis de 2008 en España. En este sentido, justifica el poco éxito de grupos callejeros antes de la crisis porque los consumidores no podían comprender el alcance de algo que no habían vivido todavía. En consecuencia, justifica que el teatro es una herramienta de educación social en la que el espectador es considerado parte activa de la obra y a través de la cual se puede manifestar el activismo social.

Volviendo a los temas sociales, María José Hellín García, recoge en el capítulo octavo el planteamiento de pensadores como Thoreau, Russell o Rawls para justificar la necesidad de llevar a cabo acciones de desobediencia civil en pro de la resistencia social. Centrándose en las asociaciones $\mathrm{V}$ de Vivienda y la Plataforma de Afectados por la Hipoteca (PAH), Hellín analiza las reivindicaciones relacionadas con el derecho a la vivienda y los desahucios forzosos, tales como los escraches o la Obra Social. Esta última es, en palabras de la autora, la mejor representación de este activismo por necesitar de la actuación común para la recuperación colectiva. A pesar de basar perfectamente su argumentación en el marco de la legalidad española, Hellín advierte de conductas aporofóbicas y vulneración de derechos y libertades a través de la Ley de Seguridad Ciudadana sin especificar su alcance.

En el capítulo 9, Raquel Vega-Durán, profundiza en la identidad del refugiado en España. La autora comienza analizando la diferencia social y legal que implica ser migrante o refugiado para enlazar con la perspectiva que la sociedad tiene de cada uno de ellos, despertando la del refugiado gran interés en los activistas. Apoya este argumento en campañas como \#Sickofwaiting o \#VenidYa que denuncian la falta de compromiso por parte de las instituciones públicas, el uso recurrente del refugiado en diversas manifestaciones literarias y exposiciones 0 performances que buscan la empatía de sus consumidores. Aunque es evidente que el eje del capítulo es el activismo, es difícil comprender la necesidad de esta respuesta social alrededor del refugiado sin sentar las bases de esta problemática.

El autor del décimo capítulo, Sergi Rivero-Navarro, indaga en las características del movimiento independentista catalán para compararlo con el $15 \mathrm{M} \mathrm{y,}$ de este modo, analizarlo como una manifestación más de activismo. El autor habla de represión, de derrocamiento del Gobierno catalán tras la aplicación del artículo 155 de la Constitución española y de deshumanización de los activistas catalanes. A través de reproches de políticos del gobierno español, como la comparación de sus acciones con las de un grupo terrorista por parte de Pablo Casado, y la enumeración de los valores democráticos que tendría una Cataluña independiente, quiere hacer entender al lector la necesidad de esta lucha. Lo que no apunta RiveroNavarro es el malestar social que este sector de la sociedad catalana está generando en los propios catalanes, las acciones no pacíficas que grupos radicales llevaron a cabo en Barcelona en días que él mismo señala, como el 27 de septiembre y el 3 de octubre de 2017, o la paralización del Parlamento de Cataluña.

En el undécimo capítulo, Pablo Martínez Diente demuestra cómo el activismo político actual está directamente influido por una Guerra Civil española aparentemente inconclusa. Lo que más remarca el autor es el sorprendente influjo de alusiones a momentos tanto pre como postbélicos en dirigentes políticos que nacieron años después de este conflicto. Así, razona que la opresión suele ser causa de justificación de un estado de crispación, como por ejemplo cuando la dictadura de Primo de Rivera desembocó en la Segunda República. Sin embargo, expone Martínez muy acertadamente que no existe ninguna circunstancia opresiva en un espacio temporal cercano al actual que justifique la agresividad del activismo político en las recurrentes referencias bélicas. Para comprender este comportamiento, recupera la teoría marxista del fetichismo de mercadería según la cual la propia Guerra Civil es el producto y el guerracivilismo, más que una mercancía, es un "fetiche con propiedades fantasmagóricas" (192). Martínez deja al lector cerca de conocer más sobre la resolución de este recurrente fetiche tras anunciar la existencia de una alternativa basada en la honra a todas las víctimas y la valoración objetiva de la historia.

Finalmente, en el capítulo doce, Francine CateArries ofrece otro tipo de activismo relacionado con las consecuencias del franquismo, en este caso por parte de la sociedad. Mediante el análisis de AMEDE, una asociación gaditana por la recuperación de la memoria exalta la unión de los ciudadanos para conseguir tres objetivos: exhumaciones en las fosas comunes del cementerio municipal, la educación y la concienciación. En este sentido, la autora habla de la importancia de los testigos y de cómo la transmisión intergeneracional ha llegado a desencadenar intervenciones colectivas en defensa de las víctimas del franquismo. Pese a reconocer la autora que los grandes cambios vendrán con la solidaridad entre asociaciones similares, no menciona ninguna de carácter estatal que per se pudiera tener mayor relevancia. 
En definitiva, este libro ofrece una aproximación a las diferentes respuestas de la sociedad española ante los temas más críticos del siglo XXI. Mediante un discurso objetivo, académico y acertadamente justificado, el lector es capaz de seguir de manera fluida el hilo conductor del activismo español. Lo más destacable es la variedad y las diversas perspectivas desde las que se analiza esta militancia. De este modo, Todos a movilizarse favorece a sectores, dentro y fuera de la academia, tan dispares como politólogos, economistas o filólogos, entre otros.

Ana Belén Álvarez (1) https://orcid.org/0000-0003-3360-0494 The University of Alabama, USA aalvarezvivo@crimson.ua.edu

Recibido: 28-04-2020 Aceptado: 23-05-2020 